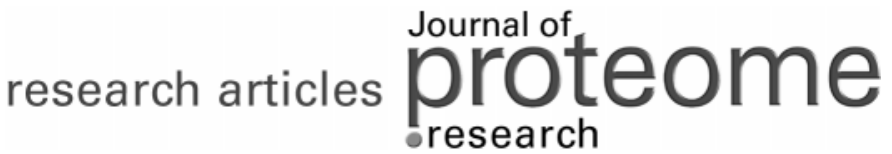

\section{Post-Translational Modifications in the Rat Lumbar Spinal Cord in Experimental Autoimmune Encephalomyelitis}

\author{
Jennifer E. Grant, ${ }^{\dagger}$ Jun Hu, ${ }^{\dagger}$ Tong Liu, ${ }^{\dagger}$ Mohit R. Jain, ${ }^{\dagger}$ Stella Elkabes, ${ }^{\ddagger, \S}$ and Hong $\mathrm{Li}^{*, \dagger}$ \\ Center for Advanced Proteomics Research and Department of Biochemistry and Molecular Biology, \\ UMDNJ-New Jersey Medical School Cancer Center, and Department of Neuroscience, \\ UMDNJ-New Jersey Medical School, Newark, New Jersey 07103, and Neurology Service, Veterans Affairs,
} East Orange, New Jersey 07018

Received January 9, 2007

\begin{abstract}
Changes in protein methylation, citrullination, and phosphorylation during experimental autoimmune encephalomyelitis, a rodent model of multiple sclerosis, were evaluated using isobaric tags for relative and absolute quantification analysis of peptides produced from normal and diseased rat lumbar spinal cords. We observed alterations in the post-translational modification of key proteins regulating signal transduction and axonal integrity. Dephosphorylation of discrete serine residues within the neurofilament heavy subunit C-terminus was observed. We report for the first time elevated citrullination of Arg27 in glial fibrillary acidic protein, which may contribute to the pathophysiology of astrocytes.
\end{abstract}

Keywords: multiple sclerosis $\bullet$ EAE $\bullet$ post-translational modification $\bullet$ iTRAQ $\bullet$ proteomics $\bullet$ mass spectrometry

\section{Introduction}

Multiple sclerosis is an autoimmune disease characterized by inflammation, demyelination, and axonal degeneration. It is generally believed that damage to both the myelin sheath and the axon is mostly the consequence of immune cell attack after infiltration into the central nervous system (CNS). However, recent studies demonstrate that changes in posttranslational modifications (PTMs) of proteins occur prior to the onset of inflammatory events. Aberrant PTMs have been associated with disease progression ${ }^{1-3}$ and may contribute to neural dysfunction. ${ }^{4}$ Due to the difficulty in isolating and detecting individual PTM sites within complex biological preparations, limited progress in defining post-translationally modified proteins has been achieved in multiple sclerosis or its experimental autoimmune encephalomyelitis (EAE) rodent model. We have successfully applied the isobaric tags for relative and absolute quantification (iTRAQ) proteomics method ${ }^{5}$ to an in vivo rodent model of multiple sclerosis to analyze the extent of PTM modulation in the EAE lumbar spinal cord.

One of the best characterized PTM changes in the CNS of multiple sclerosis patients targets the Lys-Ser-Pro repeat regions found in the C-terminus of the neurofilament heavy chain (NF$\mathrm{H}$ ), which become dephosphorylated in multiple sclerosis patients' CNS ${ }^{6-8} \mathrm{NF}-\mathrm{H}$ dephosphorylation is also found in the rat model of EAE. ${ }^{9,10}$ Despite the correlation of NF-H dephosphorylation with axonal damage, it remains unclear which specific phosphorylation site(s) may be involved. In addition, enhanced levels of citrullination, which is the deimination of

\footnotetext{
* To whom correspondence should be addressed. Phone: (973) 972-8396 Fax: (973) 972-5594. E-mail: liho2@umdnj.edu.

† UMDNJ-New Jersey Medical School Cancer Center.

‡ UMDNJ-New Jersey Medical School.

$\S$ Veterans Affairs.
}

arginine, have been correlated immunohistologically with areas of increased myelin damage in affected brain tissue in EAE rats. ${ }^{11}$ An independent study determined that glial fibrillary acidic protein was citrullinated in addition to several unidentified proteins, but the site(s) of citrullination were not identified. ${ }^{12}$ It is also known that citrullination may antagonize arginine methylation, ${ }^{13,14}$ defining arginine methylation as another PTM of potential interest that may also be modulated in multiple sclerosis. ${ }^{15}$

A previous study identified several PTM sites within myelin basic protein (MBP) in multiple sclerosis or its EAE mouse model using a mass spectrometric method. ${ }^{16}$ These authors determined that both methylation and citrullination of MBP were increased in the CNS of multiple sclerosis patients, while phosphorylation decreased. However, other proteins may have PTMs that become modulated as a result of disease. Use of a state-of-the-art proteomics approach such as the iTRAQ method ${ }^{5}$ allows assessment of protein PTM events on a global scale, providing both quantification and site-specific information for each individual peptide. iTRAQ analysis is particularly suited to the study of PTM changes during EAE because (1) tandem mass spectrometry (MS/MS) can be used to identify PTMs, the site of modification, and the peptide that was modified, and (2) iTRAQ tagging allows semiquantitative assessment of the extent of formation of each PTM event as a result of disease.

In a recent study, we applied iTRAQ analysis to delineate the differential expression profiles of a large number of proteins extracted from rat lumbar spinal cords, with particular emphasis on proteins that play a role in neuroprotection, neurodegeneration, and neuroimmune interactions. ${ }^{17}$ As an extension of this work, we now present analysis of the site-specific changes in protein methylation, citrullination, and phosphorylation that may have occurred during EAE. 


\section{Experimental Section}

Sample Preparation, iTRAQ Labeling, and Analysis. Twomonth-old Lewis rats were immunized with MBP emulsified in complete Freund's adjuvant (CFA) or CFA containing vehicle according to Nicot et al. ${ }^{18}$ Lumbar spinal cords, the region most affected by EAE, were harvested when EAE-induced rats showed hind limb paralysis. The iTRAQ labeling procedure was performed according to Liu et al. ${ }^{17}$ For each of four individually prepared samples representing two control and two EAE tissue preparations, $90 \mu \mathrm{g}$ of soluble extract from spinal tissue was subjected to the ITRAQ protocol that required sequential reduction, alkylation, trypsin digestion, and iTRAQ labeling. This sample labeling strategy allows the iTRAQ reporter ions at $m / z 114$ and 115 to report on two independent control experiments representing two individual animals, while the reporter ions at $\mathrm{m} / z 116$ and 117 yielded data from two unique EAE animals, permitting relative quantification. After iTRAQ labeling, the four uniquely labeled samples were combined, and peptide species were fractionated using strong-cationexchange chromatography followed by reversed-phase chromatography. ${ }^{17}$ The eluate was analyzed on a 4700 proteomics analyzer tandem mass spectrometer (Applied Biosystems, ABI, Foster City, CA) in the positive ion mode using internal mass calibration with Glu-fibrinogen peptide and $\mathrm{ACTH}^{18-39}$ as described. ${ }^{19}$

Data Processing and Bioinformatics. To identify peptides, 13834 MS/MS spectra were analyzed using the GPS Explorer server software suite (ABI) to organize and submit data to the MASCOT search engine v. 1.9 (Matrix Science, London, U.K.). Potential matches were scored against the International Protein Index database v. 3.23 (IPI, http://www.ebi.ac.uk/IPI) for Rattus norvegicus proteins. For all analyses, the precursor mass error tolerance was set to $50 \mathrm{ppm}$, the MS/MS mass error tolerance was set to $0.3 \mathrm{Da}$, two missed cleavages were allowed, and iTRAQ labeling of peptide N-termini as well as modification of cysteine with $S$-methylmethanethiosulfonate were set as fixed modifications. iTRAQ derivatization at lysine was set as a fixed modification except in the case of lysine methylation, where it was a variable modification. In all instances, iTRAQ labeling of tyrosines and oxidation of methionines were submitted as variable modifications. Parameters for individual PTM analyses were as follows: analysis of arginine methylation was performed separately from that of lysine methylation, and in each case the potential PTM modification was set as a variable modification. To identify phosphorylated peptides, phosphorylation at S, T, or Y was allowed as a variable modification. For citrullinated peptides, deimination of arginine was set as a variable modification.

From the list of peptide matches generated by GPS that had a confidence interval $>80 \%$, each PTM-containing peptide was further evaluated against any potential assignment of the same spectral data generated from the analogous non-PTM search, using in-house Perl scripts ${ }^{19}$ that filtered out PTM peptide assignments that were inferior to the non-PTM assignments. From each list of PTM-containing peptides, individual MS/MS spectra were confirmed manually using the Data Explorer software suite $(\mathrm{ABI})$, and their assignments are reported (Supporting Information (SI) Figure S1). Normalized iTRAQ ratios were calculated as described previously. ${ }^{17}$

2-DE and Western Blotting Analysis of NF-H Phosphorylation. Neurofilaments were prepared as described ${ }^{20}$ Briefly, 20 $\mathrm{mg}$ of tissue was homogenized in $1 \mathrm{~mL}$ of a buffer composed of $1 \%$ Triton X-100, $0.5 \mathrm{M} \mathrm{NaCl}, 0.5 \mathrm{M}$ sucrose, $5 \mathrm{mM} \mathrm{KH}_{2} \mathrm{PO}_{4}$,
$10 \mathrm{mM} \mathrm{MgCl}_{2}$, $2 \mathrm{mM}$ EGTA, $1 \mathrm{mM}$ EDTA, and $0.1 \%$ protease inhibitor cocktail (Sigma), pH 7.0. This process was repeated until myelin was depleted. Neurofilaments were solubilized from the Triton-insoluble pellet by agitation for $1 \mathrm{~h}$ at room temperature in $10 \mathrm{mM}$ Tris $\cdot \mathrm{HCl}, 10 \mathrm{mM}$ dithiothreitol (DTT), and $8 \mathrm{M}$ urea, $\mathrm{pH}$ 7.0. Neurofilament preparations were desalted using the Ready-Prep kit (Bio-Rad, Hercules, CA), resuspended in 2-DE rehydration buffer (7 M urea, $2 \mathrm{M}$ thiourea, $2 \%$ CHAPS), and adjusted to $200 \mathrm{ng}$ in a total volume of $187 \mu \mathrm{L}$, using the Bradford method. ${ }^{21}$ The yield of neurofilament proteins was confirmed by SDS-PAGE combined with Sypro Ruby staining. Isoelectric focusing ${ }^{22}$ was performed on a Protean isoelectric focusing apparatus (Bio-Rad), using immobilized linear $\mathrm{pH}$ gradient (IPG) Readystrips ( $\mathrm{pH} 3-10$ ) according to the manufacturer's protocol, a procedure requiring subsequent reduction of the Readystrips with DTT followed by alkylation with iodoacetamide. Each IPG strip was trimmed to fit a minigel apparatus (BioRad) by removing $\sim 1.5 \mathrm{~cm}$ of material from the acidic $\mathrm{pH}$ end and $\sim 2.5 \mathrm{~cm}$ of material from the basic $\mathrm{pH}$ end and then electrophoresed on a $6 \%$ SDS-PAGE gel. For Western analysis, ${ }^{23}$ the gels were blotted onto nitrocellulose membranes using a Protean II xi minigel transblot apparatus (Bio-Rad). The SMI32 antibody ${ }^{24}$ (1:10000, Sternberger Monoclonals, Lutherville, MD) directed against dephosphorylated C-terminal epitopes within NF-H (DeNF-H) was used as the primary antibody, and HRP-conjugated goat antimouse IgG (1:10000, Upstate Scientific) was used as the secondary antibody. DeNF-H was visualized using the Western Lightning chemiluminescence kit (Perkin-Elmer, Boston, MA).

\section{Results and Discussion}

Lysine-Methylated Peptides. A total of 20 lysine-methylated peptides were detected in this study. Of the 10 found to undergo change in EAE (Table 1), 3 demonstrated elevated dimethylation levels, including plastin-3 (1.8), elongation factor $1-\alpha 2$ (1.4), and the R3H domain isoform 3 (1.2). In Figure 1A, the iTRAQ reporter region demonstrating the EAE-induced increase in lysine dimethylation of plastin-3 (442-449) at Lys444 is presented, along with the MS/MS spectrum allowing peptide identification and PTM assignment. Each assigned spectrum is included in SI Figure S1A-C. Interestingly, plastin- 3 cross-links with actin to generate tight bundles of actin and is found in the CNS. ${ }^{25}$ Although a role for this protein in the etiology of multiple sclerosis has not been postulated, it is notable that anti-plastin antibodies have been identified in Kawasaki disease, a heart/vascular disease of unknown origin that has autoimmune components. ${ }^{26}$

Hypomethylation of specific proteins may be associated with multiple sclerosis. ${ }^{14}$ Of the seven lysine-methylated peptides exhibiting reductions in methylation, three were identified as having one monomethylated lysine, including the "s" subunit of complement component 1 (0.79), the $\rho$-associated kinase, isoform 1 (0.77), and the peroxisome proliferator-activated receptor $\delta$-subunit (PPAR- $\delta$ ) (0.69). One hypomethylated peptide, the discs large homologue 7 protein $(0.70)$, contained both one monomethylation and one dimethylation event. The three remaining peptides were identified as having one lysine dimethylation event: transcription initiation factor TFIID, subunit 5 (0.79), the early endosome antigen 1 (EEAl; 0.76), and phosphoglycerate mutase 2 (0.71). Assigned spectra are reported in SI Figure S1D-J. Notably, the reduction in lysine methylation of the "s" subunit of complement 1 is of great interest since this protease initiates formation of the membrane 
Table 1. Lysine- and Arginine-Methylated Peptides

\begin{tabular}{|c|c|c|c|c|c|c|c|}
\hline peptide $^{a}$ & protein & $\begin{array}{c}\text { accession } \\
\text { number }\end{array}$ & $\begin{array}{l}\text { amino acid } \\
\text { residues }\end{array}$ & $\begin{array}{l}\text { calcd mass } \\
\qquad(\mathrm{m} / \mathrm{z})\end{array}$ & $\begin{array}{c}\text { obsd mass } \\
\quad(m / z)\end{array}$ & $\begin{array}{l}\text { error } \\
\text { (ppm) }\end{array}$ & $\begin{array}{c}\text { ITRAQ } \\
\text { ratio }\end{array}$ \\
\hline \multicolumn{8}{|c|}{ Lysine-Methylated Peptides } \\
\hline VNK ${ }^{\#} \mathrm{PPYPK}$ & plastin-3 & IPI00210234 & $442-449$ & 1258.777 & 1258.719 & -46 & 1.8 \\
\hline GSFK"YAWVLDK & elongation factor $1-\alpha 2$ & IPI00325281 & $52-62$ & 1629.925 & 1629.927 & 1 & 1.4 \\
\hline GDSSGSSK ${ }^{\#}$ SIGR & $\mathrm{R} 3 \mathrm{H}$ domain isoform 3 & IPI00763599 & $391-402$ & 1309.683 & 1309.736 & 40 & 1.2 \\
\hline GAK ${ }^{\mathrm{O}}$ LPITSLEK & complement component 1 , s subunit & IPI00199519 & $590-600$ & 1458.914 & 1458.863 & -35 & 0.79 \\
\hline VLSSLTK" K & transcription initiation factor TFIID, sub & IPI00361559 & $279-286$ & 1191.792 & 1191.826 & 28 & 0.79 \\
\hline TSNIKLDKOIMK & $\rho$-associated protein kinase 1 , isoform 1 & IPI00211045 & $455-465$ & 1608.960 & 1608.929 & -19 & 0.77 \\
\hline SK ${ }^{\#}$ YDEEKGLR & early endosome antigen 1 & IPI00768104 & $177-186$ & 1396.756 & 1396.691 & -46 & 0.76 \\
\hline ALPFWNEEIAPK ${ }^{\#} \mathrm{IK}$ & phosphoglycerate mutase 2 & & 75 & 197 & 1972 & 44 & 0.71 \\
\hline DVNK ${ }^{\mathrm{O}} \mathrm{IK}^{\#} \mathrm{VK}$ & discs large homologue 7 & IPI00766460 & $703-710$ & 1273.845 & 1273.889 & 34 & 0.70 \\
\hline MPEAEKO$^{\circ} \mathrm{R}$ & PPAR- $\delta$ protein & IPI00325169 & $147-153$ & 1018.547 & 1018.505 & -42 & 0.69 \\
\hline \multicolumn{8}{|c|}{ Arginine-Methylated Peptides } \\
\hline FLQR ${ }^{O}$ YAILTK & myosin $1 \mathrm{E}$ & IPI00207988 & $632-641$ & 1554.962 & 1554.946 & -10 & 3.9 \\
\hline $\mathrm{LER}^{\#} \mathrm{MR}^{\#} \mathrm{LVR}$ & nephrocystin 4 orthologue & IPI00764323 & $848-855$ & 1288.801 & 1288.843 & 33 & 1.5 \\
\hline SRAHVPGR $^{\circ} \mathrm{GR}$ & protein phosphatase 1 regulatory subunit 3D & IPI00359691 & $53-62$ & 1250.731 & 1250.708 & -18 & 1.4 \\
\hline EQPCVCLQER $^{\# A R}$ & EGF-like domain-containing protein 4 & IPI00365661 & $2405-2416$ & 1695.788 & 1695.828 & 23 & 1.3 \\
\hline KER ${ }^{\#}$ QLILK & centrosome-associated protein 350 & IPI00207361 & $1748-1755$ & 1488.001 & 1487.982 & -12 & 0.57 \\
\hline
\end{tabular}

${ }^{a}$ Key: O, monomethylated residue; \#, dimethylated residue.

attack complex that is the hallmark of the classical complement pathway of immune response and inflammation. ${ }^{27}$ Also, hypomethylation of PPAR- $\delta$ is noteworthy, since this transcription factor promotes oligodendrocyte survival and differentiation, ${ }^{28,29}$ primarily through the induction of the neuronal cell adhesion molecule. ${ }^{30}$ In the case of EEA1, antibodies to this vesicular trafficking protein have been identified in several neurological diseases. ${ }^{31,32}$

Arginine-Methylated Peptides. Of the 11 peptides found to have methylated arginines, only 1 showed diminished methylation and 4 were found at enhanced levels as a result of EAE (Table 1). Both a peptide from myosin 1E (3.9; Figure 1B) and a peptide from the protein phosphatase 1 regulatory subunit 3D (1.5) were monomethylated at increased levels, while the nephrocystin 4 orthologue (1.5) was dimethylated. One dimethylated peptide (1748-1755) from the centrosome-associated protein 350 (CAP350; 0.57) demonstrated diminished dimethylation. Spectral assignments are reported in SI Figure S1K-O. Curiously, myosin $1 \mathrm{E}$ is a nonmuscle myosin associated with focal adhesions in B-lymphocytes, ${ }^{33}$ and hypermethylation may potentially serve as a marker for lymphocyte activity. Nephrocystin, found within focal adhesion signaling complexes in cilia, ${ }^{34}$ is primarily associated with the renal disease nephronophthisis, ${ }^{35}$ while a subset of nephronophthisis patients also experience visual (retinitis pigmentosa) and neurological (tremor, ataxia) symptoms. ${ }^{36}$ Nephrocystin has been found in mouse brain $^{37}$ and shown to be a component of the nuclear centrosome whose mutation leads to the neurological condition Joubert syndrome. ${ }^{38}$ This is the first report identifying a nephrocystin component peptide in the rat brain. CAP350 is a centrosomal protein known to anchor the microtubular network that regulates cell shape and motility ${ }^{39}$ and was found hypomethylated in this iTRAQ study. Curiously, PPAR- $\delta$, which demonstrated reduced lysine methylation in EAE (Table 1), is recruited to distinct nuclear locations by CAP350. ${ }^{40}$ The biological link between CAP350 and PPAR- $\delta$ provides an intriguing clue as to how PTM changes could progressively affect the CNS in EAE.

Arginine-Citrullinated Peptides. Elevated citrullination has been associated with multiple sclerosis ${ }^{16}$ and EAE. ${ }^{11,12} \mathrm{~A}$ total of 21 peptides were found citrullinated (Figure S1P-R in Supporting Information), but only 3 were affected by EAE (Table 2). The peptide 217-223 of the Ser/Thr protein kinase RIO3, which is an atypical kinase involved in ribosome bio- genesis, ${ }^{41,42}$ had an elevated iTRAQ ratio of 2.2 (Figure 1C). Also, we identified enhanced citrullination at Arg27 of glial fibrillary acidic protein (GFAP), because the peptide $22-34$ had an iTRAQ ratio of 1.3. This is the first site-specific assessment of the citrullination of GFAP, a protein known to be hypercitrullinated in the EAE model. ${ }^{12}$ The only peptide registering diminished citrullination as a consequence of EAE is the peptide 504-516 of ribophorin 1 (0.74). Ribophorin is a subunit of an oligosaccharyltransferase required for correct glycosylation of nascent polypeptides. ${ }^{43,44}$

Serine-Phosphorylated Peptides. Of the 12 phosphorylated peptides that were identified, 6 had iTRAQ ratios altered during EAE (Table 2), and their spectra are reported in SI Figure S1S$\mathrm{X}$. The peptide $24-33$ from the $60 \mathrm{kDa}$ lysophospholipase (1.3) experienced increased phosphorylation of Ser24, an intriguing finding because Osoegawa et al. $^{45}$ reported that the lowered activity of this enzyme caused by a missense mutation may predict the severity of multiple sclerosis in a cohort of Japanese patients. We identified that Ser473 of neurofilament light subunit (NF-L) became dephosphorylated in EAE, from evaluation of the ITRAQ ratio of 0.67 for the peptide $464-482$. As the major site of phosphorylation within the NF-L C-terminus, ${ }^{46}$ Ser473 is the substrate of casein kinase II. ${ }^{47}$

Four out of five peptides found to have diminished serine phosphorylation originated from NF-H, including the peptides 642-653 (or 582-593, 0.75, Figure 1D), 756-765 (0.80), 750761 (or $672-683,0.77$ ), and $875-886$ (0.71). Although it was reported previously that NF-H phosphorylation is diminished in $\mathrm{EAE}^{9,10}$ and multiple sclerosis, ${ }^{6-8}$ these data represent the first report of site-specific changes in the extent of NF-H phosphorylation due to EAE. The four residues dephosphorylated during EAE are Ser648 (or Ser588), Ser756 (or Ser678), Ser762, and Ser880, all residing in the C-terminal Lys-Ser-Pro repeat region known to regulate axonal caliber. The human cognates of Ser648, Ser762, and Ser880 are present in human NF-H and are phosphorylated in healthy $\mathrm{CNS},{ }^{48}$ as indicated by the sequence homology between rat and human sequences (SI Figure S2). However, this is the first report documenting site-specific changes in the phosphorylation of Lys-Ser-Pro repeats within NF-H as a result of EAE.

Western Blotting of NF-H Confirms Dephosphorylation. To confirm the validity of our experimental system and procedures, the phosphorylation state of NF-H was evaluated by 2D 
A. Plastin-3 [442-449] : lysine-methylated.
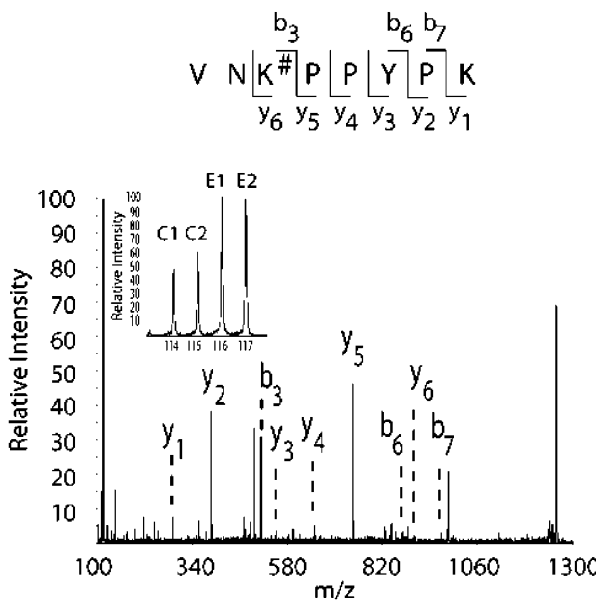

C. Ser/Thr kinase RIO3 [217-223] : arginine-citrullinated.

$$
\begin{gathered}
b_{3} b_{4} b_{5} b_{6} \\
S A R^{+} \frac{L}{y_{4}} \frac{H}{y_{3}} \frac{E}{y_{2}} \frac{K}{y_{1}} K_{1}
\end{gathered}
$$

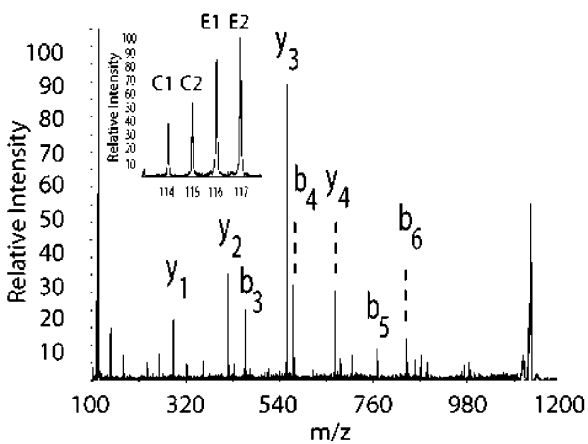

B. Myosin 1E [632-641] : arginine-methylated.

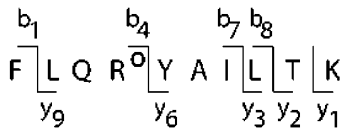

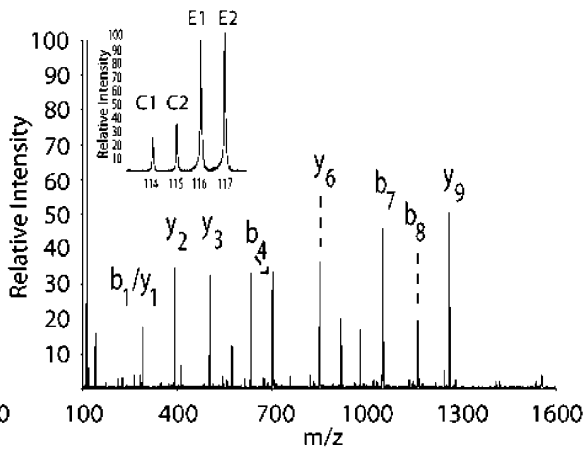

D. Neurofilament H [582-593] or [642-653] : serine-phosphorylated.
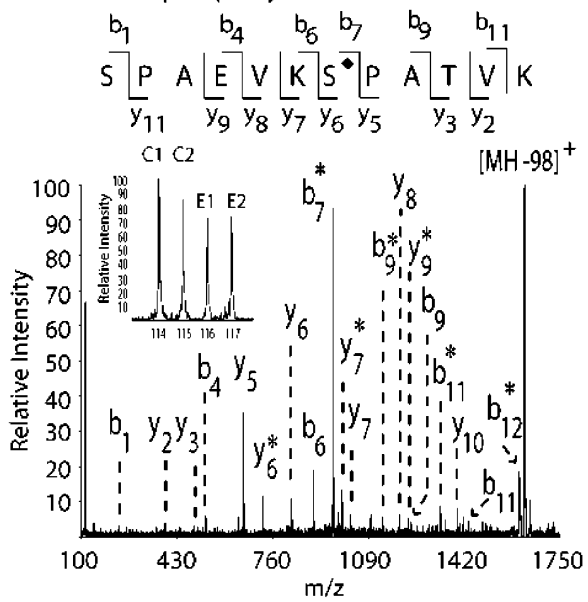

Figure 1. MS/MS spectra of PTM peptides. This figure illustrates the iTRAQ region and peptide region of the MS/MS spectrum for one representative peptide of each PTM class: (A) plastin-3 (442-449), a peptide lysine-dimethylated at Lys444 (\#); (B) myosin 1E (632641), a peptide arginine-methylated at $\operatorname{Arg} 635$ (O); (C) serine/threonine protein kinase RIO3 (217-223), a peptide citrullinated at Arg219 (+); (D) NF-H (642-653 or 582-593), a peptide serine-phosphorylated at Ser648 (or Ser588) ( $\$$ ). For each peptide, the MS/MS spectrum indicates $\mathrm{N}$-terminal (b-series) and $\mathrm{C}$-terminal ( $\mathrm{y}$-series) ions that were identified. Peptide fragments derived from neutral loss of $\mathrm{H}_{3}$ $\mathrm{PO}_{4}(98 \mathrm{Da})$ are also indicated $(*)$. Inset: For each peptide, the iTRAQ reporter ion region $(\mathrm{m} / \mathrm{z} 114-117)$ is illustrated, indicating the

\begin{tabular}{|c|c|c|c|c|c|c|c|}
\hline peptide $^{a}$ & protein & $\begin{array}{c}\text { accession } \\
\text { number }\end{array}$ & $\begin{array}{l}\text { amino acid } \\
\text { residues }\end{array}$ & $\begin{array}{l}\text { calcd mass } \\
\qquad(\mathrm{m} / \mathrm{z})\end{array}$ & $\begin{array}{c}\text { obsd mass } \\
(\mathrm{m} / \mathrm{z})\end{array}$ & $\begin{array}{l}\text { error } \\
\text { (ppm) }\end{array}$ & $\begin{array}{l}\text { ITRAQ } \\
\text { ratio }\end{array}$ \\
\hline \multicolumn{8}{|c|}{ Citrullinated Peptides } \\
\hline $\mathrm{SAR}^{+} \mathrm{LHEK}$ & Ser/Thr kinase RIO3 & IPI00364947 & $217-223$ & 1129.657 & 1129.647 & -9 & 2.2 \\
\hline GHGPTR $^{+}$HLGTIPR & glial fibrillary acidic protein & IPI00190943 & $22-34$ & 1543.858 & 1543.825 & -21 & 1.3 \\
\hline $\mathrm{QSR}^{+}$DISTLNSGKK & ribophorin 1 & IPI00204365 & $504-516$ & 1867.062 & 1867.088 & 14 & 0.74 \\
\hline \multicolumn{8}{|c|}{ Phosphorylated Peptides } \\
\hline$S • E G G V L V P G R$ & lysophospholipase & IPI00207299 & $24-33$ & 1194.600 & 1194.625 & 21 & 1.3 \\
\hline SPVEVKS॰PEK & neurofilament $\mathrm{H}$ & IPI00188524 & $756-765$ & 1611.873 & 1611.863 & -6 & 0.80 \\
\hline SPAEAKS PVEVK & neurofilament $\mathrm{H}$ & IPI00188524 & $750-761^{*}$ & 1753.947 & 1753.921 & -15 & 0.77 \\
\hline SPAEVKS PATVK & neurofilament $\mathrm{H}$ & IPI00188524 & $642-653^{\wedge}$ & 1725.952 & 1725.936 & -9 & 0.75 \\
\hline KEEVKS•PVEEVK & neurofilament $\mathrm{H}$ & IPI00188524 & $875-886$ & 2057.139 & 2057.156 & 8 & 0.71 \\
\hline AEEAKDEPPS`EGEAEEEEK & neurofilament L & IPI00231302 & $464-482$ & 2615.162 & 2615.151 & -4 & 0.67 \\
\hline
\end{tabular}
two signals from the controls $(\mathrm{C} 1, \mathrm{C} 2)$ and the two from EAE tissues (E1, E2).

Table 2. Arginine-Citrullinated and Serine-Phosphorylated Peptides

${ }^{a}$ Key: + , citrullinated residue; ${ }^{\bullet}$, phosphorylated residue; ${ }^{*}$, identical sequence at $672-683 ;{ }^{\wedge}$, identical sequence at $582-593$.

gel, followed by Western blotting (Figure 2), using the SMI-32 antibody known to interact specifically with nonphosphorylated epitopes in the Lys-Ser-Pro repeat region of NF-H. This antibody recognizes only the dephosphorylated form, DeNF-H, but does not recognize its highly phosphorylated cognate.
Consistent with previous reports in the literature, DeNF-H was not detected in control samples (Figure 2A), but was readily detected in EAE spinal cord (Figure 2B). DeNF-H was visualized in the EAE samples as a discrete region having a $\mathrm{pI}$ of $\sim 6.3$ and a molecular weight of $\sim 190 \mathrm{kDa}$. 
A. Control Tissue.

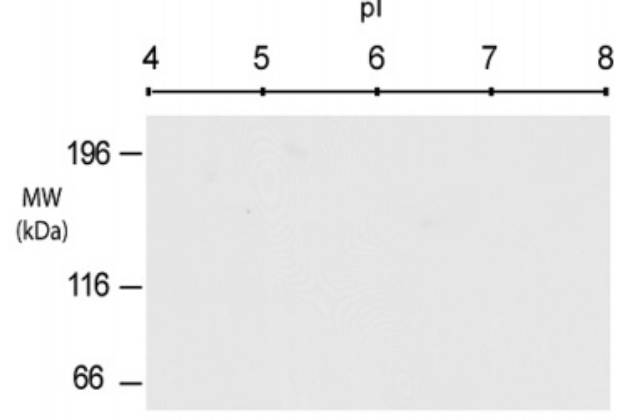

B EAETissue.

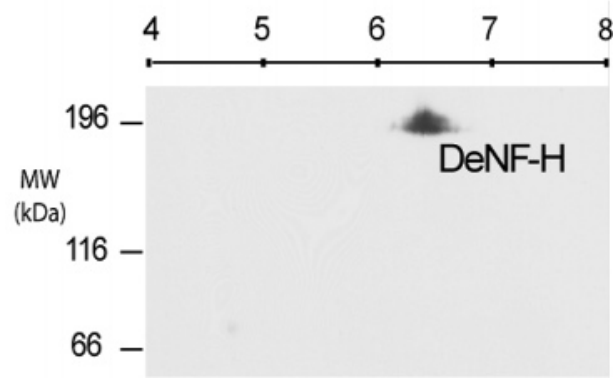

Figure 2. Evaluation of NF-H dephosphorylation by Western blotting. Triton-insoluble neurofilament extracts were prepared from lumbar sections, according to the procedure described in the Experimental Section. Individual aliquots of each preparation were subjected to isoelectric focusing followed by electrophoresis on $6 \%$ SDS-PAGE gels. Western blotting using the SMI-32 IgG antibody specific for DeNF-H was used to evaluate the control (A) and $E A E(B)$ tissues.

\section{Conclusions}

We have observed several alterations in PTMs during EAE in proteins that participate in regulation of neurons, glia, and immune cells. For the first time, EAE-induced citrullination of GFAP at Arg27 is reported. Additionally, dephosphorylation of discrete serine residues within NF-H was observed. Additional proteins were identified, having PTMs affected by EAE, and many of these merit further investigation, including plastin-3, nephrocystin, CAP350, and PPAR- $\delta$. Several proteins that have been reported to undergo PTM changes in either EAE or multiple sclerosis were not detected in this iTRAQ analysis and may reflect the tendency, in iTRAQ experiments, to identify high-abundance proteins. Although outside of the present work, fractionation of the samples prior to iTRAQ analysis, including protein separation techniques, organelle isolation, and/or PTM-directed affinity capture prior to iTRAQ analysis, could enhance our ability to identify and quantify the levels of additional proteins whose PTM status is affected by EAE.

Acknowledgment. We thank Drs. Martha Vestling and Kevin Schey for many helpful discussions concerning this paper. This research is supported in part by NIH Grants NS046593 to H.L. and NS046363 to S.E.

Supporting Information Available: MS/MS assignments for all EAE-sensitive PTM peptides described in this work and sequence alignment of the rat and human NF-H C-termini. This material is available free of charge via the Internet at http://pubs.acs.org.

\section{References}

(1) Anderton, S. M. Post-translational modifications of self antigens: implications for autoimmunity. Curr. Opin. Cell Biol. 2004, 16 (6), 753-8.

(2) Gyorgy, B.; Toth, E.; Tarcsa, E.; Falus, A.; Buzas, E.I. Citrullination: A posttranslational modification in health and disease. Int. J. Biochem. Cell Biol. 2006, 38 (10), 1662-77.

(3) Harauz, G.; Ishayama, N.; Hill, C. M. D.; Bates, I. R.; Libich, D. S.; Fares, C. Myelin basic protein-diverse conformational states of an intrinsically unstructured protein and its roles in myelin assembly and multiple sclerosis. Micron 2004, 35 (7), 503-542.

(4) Qi, X.; Lewin, A. S.; Sun, L.; Hauswirth, W. W.; Guy, J. Mitochondrial protein nitration primes neurodegeneration in experimental autoimmune encephalomyelitis. J. Biol. Chem. 2006, 281 (42), 31950-62.

(5) Ross, P. L.; Huang, Y. L. N.; Marchese, J. N.; Williamson, B.; Parker, K.; Hattan, S.; Khainovski, N.; Pillai, S.; Dey, S.; Daniels, S.; Purkayastha, S.; Juhasz, P.; Martin, S.; Bartlet-Jones, M.; He, F.; Jacobson, A.; Pappin, D. J. Multiplexed protein quantitation in Saccharomyces cerevisiae using amine-reactive isobaric tagging reagents. Mol. Cell. Proteomics 2004, 3 (12), 1154-69.

(6) Petzold, A. Neurofilament phosphoforms: Surrogate markers for axonal injury, degeneration and loss. J. Neurol. Sci. 2005, 233 (12), 183-198.

(7) Werner, P.; Pitt, D.; Raine, C.S. Multiple sclerosis: Altered glutamate homeostasis in lesions correlates with oligodendrocyte and axonal damage. Ann. Neurol. 2001, 50 (2), 169-80.

(8) Trapp, B. D.; Peterson, J. P.; Ransohoff, R. M.; Rudick, R.; Mork, S.; Bo, L. Axonal transection in the lesions of multiple sclerosis. N. Engl. J. Med. 1998, 338 (5), 278-85.

(9) Pitt, D.; Werner, P.; Raine, C. S. Glutamate excitotoxicity in a model of multiple sclerosis. Nat. Med. 2000, 6 (1), 67-70.

(10) Brand-Schieber, E.; Werner, P.; Iacobas D. A.; Iacobas, S.; Beelitz M.; Lowery, S. L.; Spray, D. C.; Scemes, E. Connexin43, the major gap junction protein of astrocytes, is down-regulated in inflamed white matter in an animal model of multiple sclerosis. J. Neurosci. Res. 2005, 80 (6), 798-808.

(11) Raijmakers, R.; Volgenzangs, J.; Croxford, J. L.; Wesseling, P.; Van Venrooij, W. J.; Pruijn, G. J. M. Citrullination of central nervous system proteins during the development of experimental autoimmune encephalomyelitis. J. Comp. Neurol. 2005, 486, (3), $243-53$.

(12) Nicholas, A. P., Sambandam, T.; Echols, J. D.; Barnum, S. R. Expression of citrullinated proteins in murine experimental autoimmune encephalomyelitis. J. Comp. Neurol. 2005, 486 (3), 254-266.

(13) Pritzker, L. B.; Joshi, S.; Gowan, J. J.; Harauz, G.; Moscarello, M. A. Deimination of myelin basic protein. 1. Effect of deimination of arginyl residues of myelin basic protein on its structure and susceptibility to digestion by cathepsin D. Biochemistry 2000, 39 (18), 5374-81.

(14) Cuthbert, G. L.; Daujat, S.; Snowden, A. W.; Erdjument-Bromage, H.; Hagiwara, T.; Yamada, M.; Schneider, R.; Gregory, P. D.; Tempst, P.; Bannister, A. J.; Kouzarides, T. Histone deimination antagonizes arginine methylation. Cell 2004, 118 (5), 545-53.

(15) Bedford, M. T.; Richard, S. Arginine methylation: An emerging regulator of protein function. Mol. Cell 2005, 18 (3), 263-72.

(16) Kim, J. K.; Mastronardi, F. G.; Wood, D. D.; Lubman, D. M.; Zand, R.; Moscarello, M. A. Multiple sclerosis-An important role for post-translational modifications of myelin basic protein in pathogenesis. Mol. Cell. Proteomics 2003, 2 (7), 453-62.

(17) Liu, T; Donahue, K. C.; Hu, J.; Kurnellas, M. P.; Grant, J. E.; Li, H.; Elkabes, S. Identification of differentially expressed proteins in experimental autoimmune encephalomyelitis (EAE) by proteomic analysis of the spinal cord. J. Proteome Res. 2007, in press.

(18) Nicot, A.; Ratnaker, P. V.; Ron, Y.; Chen, C. C.; Elkabes, S. Regulation of gene expression in experimental autoimmune encephalomyelitis indicates early neuronal dysfunction. Brain 2003, 126 (2), 398-412.

(19) Hu, J.; Qian, J.; Borisov, O.; Pan, S. Q.; Li, Y.; Liu, T.; Deng, L. W.; Wannemacher, K.; Kurnellas, M.; Patterson, C.; Elkabes, S.; Li, H. Optimized proteomic analysis of a mouse model of cerebellar dysfunction using amine-specific isobaric tags. Proteomics 2006, 6 (15), 4321-34

(20) Funchal, C.; de Almeida, L. M. V.; Loureiro, S. O.; Vivian, L.; Pelaez, P. D.; Pessutto, F. D. B.; Rosa, A. M.; Wajner, M.; Pureur, R. P. In vitro phosphorylation of cytoskeletal proteins from cerebral cortex of rats. Brain Res. Protoc. 2003, 11 (2), 111-8. 
(21) Bradford, M. M. Rapid And Sensitive Method For Quantitation Of Microgram Quantities Of Protein Utilizing Principle Of ProteinDye Binding. Anal. Biochem. 1976, 72 (1-2), 248-54.

(22) O'Farrell, P. H. High resolution two-dimensional electrophoresis of proteins. J. Biol. Chem. 1975, 250 (10), 4007-21.

(23) Towbin, Z.; Staehelin, T.; Gordon, J. Electrophoretic transfer of proteins from polyacrylamide gels to nitrocellulose sheets: procedure and some applications. Proc. Natl. Acad. Sci. U.S.A. 1979 76 (9), 4350-4.

(24) Sternberger, L. A.; Sternberger, N. H. Monoclonal antibodies distinguish phosphorylated and non-phosphorylated forms of neurofilaments in situ. Proc. Natl. Acad. Sci. U.S.A. 1983, 80 (19), 6126-30.

(25) Delanote, V.; Vandekerkhove, J.; Gettemans, J. Plastins: versatile modulators of actin organization in (patho)physiological cellular processes. Acta Pharmacol. Sin. 2005, 26, (7), 769-79.

(26) Kaneko, M.; Ono, T.; Matsubara, T.; Yamamoto, Y.; Ikeda, H.; Yoshiki, T.; Furukawa, S.; Nakayama, E. Serological identification of endothelial antigens predominantly recognized in Kawasaki disease patients by recombinant expression cloning. Microbiol. Immunol. 2004, 48 (9), 703-11.

(27) Barnum, S. R. Inhibition of complement as a therapeutic approach in inflammatory central nervous system (CNS) disease. Mol. Med. 1999, 5 (9), 569-582.

(28) Woods, J. W.; Tanen, M.; Figueroa, D. J. et al., Localization of PPAR delta in murine central nervous system: expression in oligodendrocytes and neurons. Brain Res. 2003, 975, (1-2), 1021.

(29) Saluja, I.; Granneman, J. G.; Skoff, R. P. PPAR delta agonists stimulate oligodendrocyte differentiation in tissue culture. GLIA 2001, 33 (3), 191-204.

(30) Lampen, A.; Grimaldi, P. A.; Nau, H. Modulation of peroxisome proliferator-activated receptor delta activity affects neural cell adhesion molecule and polysialyltransferase ST8SiaIV induction by teratogenic valproic acid analogs in F9 cell differentiation. Mol. Pharmacol. 2005, 68 (1), 193-203.

(31) Selak, S.; Braun, J. E.; Fritzler, M. J. Characterization of early endosome antigen 1 in neural tissues. Biochem. Biophys. Res. Commun. 2004, 323 (4), 1334-42.

(32) Stinton, L. M.; Eistathioy, T.; Selak, S.; Chan, E. K. L.; Fritzler, M. J. Autoantibodies to protein transport and messenger RNA processing pathways: endosomes, lysosomes, Golgi complex, proteasomes, assemblyosomes, exosomes, and GW bodies. Clin. Immunol. 2004, 110 (1), 30-44.

(33) Lindvall, J. M.; Blomberg, K. E.; Wennborg, A.; Smith, C. I. E. Differential expression and molecular characterisation of Lmo7, Myole, Sash1, and Mcoln2 genes in Btk-defective B-cells. Cell. Immunol. 2005, 235 (1), 46-55.

(34) Hildebrandt, F.; Omram, H. New insights: nephronophthisismedullary cystic kidney disease. Pediatr. Nephrol. 2001, 16 (2), 168-176.

(35) Roepman, R.; Letteboer, S. J. F.; Arts, H. H. et al., Interaction of nephrocystin-4 and RPGRIP1 is disrupted by nephronophthisis or Leber congenital amaurosis-associated mutations. Proc. Natl. Acad. Sci. U.S.A. 2005, 102 (51), 18520-25.
(36) Caridi, G.; Dagnino, M.; Rossi, A.; Valente, E. M. Nephronophthisis type 1 deletion syndrome with neurological symptoms: Prevalence and significance of the association. Kidney Int. 2006, 70 (7), 1342-7.

(37) Mollet, G.; Silbermann, F.; Delous, M.; Salomon, R.; Antignac, C.; Saunier, S. Characterization of the nephrocystin/nephrocystin 4 complex and subcellular localization of nephrocystin- 4 to primary cilia and centrosomes. Hum. Mol. Genet. 2005, 14 (5), $645-656$.

(38) Sayer, J. A.; Otto, E. A.; O’Toole, J. F. et al., The centrosomal protein nephrocystin-6 is mutated in Joubert syndrome and activates transcription factor ATF4. Nat. Genet. 2006, 38 (6), 674681.

(39) Yan, X. M.; Habedanck, R.; Nigg, E. A. A complex of two centrosomal proteins, CAP350 and FOP, cooperates with EB1 in microtubule anchoring. Mol. Biol. Cell 2006, 17 (2), 634-44.

(40) Patel, H.; Truant, R.; Rachubinski, R. A.; Capone, J. P. Activity and subcellular compartmentalization of peroxisome proliferatoractivated receptor alpha are altered by the centrosome-associated protein CAP350. J. Cell Sci. 2005, 118 (1), 175-86.

(41) LaRonde-LeBlanc, N.; Wlodower, A. A family portrait of the RIO kinases. J. Biol. Chem. 2005, 280 (45), 37297-300.

(42) LaRonde-LeBlanc, N.; Wlodower A. The RIO kinases: An atypical protein kinase family required for ribosome biogenesis and cell cycle progression. BBA-Proteins Proteomics 2005, 1754 (1-2), 14-24.

(43) Kreibich, G.; Ulrich, B. L.; Sabatini, D. D. Proteins of rough microsomal membranes related to ribosome binding. I. Identification of ribophorins I and II, membrane proteins characteristics of rough microsomes. J. Cell Biol. 1978, 77 (2), 464-87.

(44) Kelleher, D. J.; Gilmore, R. An evolving view of the eukaryotic oligosaccharyltransferase. Glycobiology 2006, 16 (4), 47R-62R.

(45) Osoegawa, M.; Niino, M.; Ochi, H.; Kikuchi, S.; Murai, H.; Fukazawa, T.; Minohara, M.; Tashiro, K.; Kira, J. Platelet-activating factor acetylhydrolase gene polymorphism and its activity in Japanese patients with multiple sclerosis. J. Neuroimmunol. 2004, 150 (1-2), 150-6.

(46) Xu, Z. S.; Liu, W. S.; Willard, M. Identification of serine-473 as a major phosphorylation site in the neurofilament polypeptideNF-L. J. Neurosci. 1990, 10 (6), 1838-46.

(47) Nakamura, Y.; Hashimoto, R.; Kashiwagi, Y.; Wada, Y.; Sakoda, S.; Miyamae, Y.; Kudo, T.; Takeda, M. Casein kinase II is responsible for phosphorylation of NF-L at Ser-473. FEBS Lett. 1999, 455 (1-2), 83-6.

(48) Jaffe, H.; Veeranna Shetty, K. T.; Pant, H. C. Characterization of the phosphorylation sites of human high molecular weight neurofilament protein by electrospray ionization tandem mass spectrometry and database searching. Biochemistry 1998, 37 (11), $3931-40$.

PR070013C 